\title{
Analisa Metode Penentuan Waktu Penggantian Komponen Undercarriage Pada Sistem Quality Track Service (QTS)
}

\author{
Ali Abrar \\ Jurusan Teknik Elektronika \\ Politeknik Negeri Balikpapan \\ Jl. Soekarno Hatta Km.8 Balikpapan Tlp. (0542) 860895 Fax. 861107 \\ Email : ali.abrar@poltekba.ac.id
}

\begin{abstract}
Determination Method Analysis of Duration Change Quality Track Service (QTS) Undercarriage component is required to compare data accurate level that resulted and predicted from depletion measurement. Undercarriage component is part that has main role on heavy equipment and usually it can be reach $60 \%$ from total maintenance cost. Besides that crushing between components that also influenced by several factors which It is relevant with soil condition, area of heavy equipment use and operational place. From the study result and data analysis as well as analysis trend component change when depletion reaches $120 \%$ with using analysis method of linear regression can be obtained duration change until 1600 hours, with exponential method 500 hours and with using polynomial method nearly 50 hours so that it can be concluded that analysis method uses polynomial have higher accurate level. The accurate level has economically aspect regard to cost inventory. When this is commutated on linear method analysis, exponential and polynomial can be obtained cost different as much as 11, 04 Milliard, 3, 45 Milliard with furthermore can be known that inventory cost budget uses polynomial method more efficient.
\end{abstract}

Keyword: Undercarriage, Trend Analysis, Polynomial method

\begin{abstract}
Abstrak
Analisa Metode Penentuan Waktu Penggantian Quality Track Service(QTS) komponen Undercarriage diperlukan untuk dapat membandingkan tingkat keakuratan data yang dihasilkan dan diprediksikan dari pengukuran keausan. Komponen Undercarriage merupakan bagian yang memiliki peranan utama pada suatu alat berat dan biasanya penggantian komponen dapat mencapai hingga 60\% dari total biaya perawatan. Selain karena terjadinya pergesekan antar komponen tingkat keausan juga dipengaruhi oleh beberapa faktor yang berkaitan dengan kondisi tanah, medan, penggunaan alat berat dan lingkungan tempat beroperasi. Dari hasil penelitan dan analisa data serta trend analisis untuk penggantian komponen ketika keausan mencapai 120\%, dengan menggunakan metode analisis regresi linier didapatkan perbedaan waktu penggantian hingga 1600 jam, dengan metode eksponensial 500 jam dan dengan metode polinomial mendekati 50 jam sehingga dapat disimpulkan bahwa metode analisis menggunakan polinomial memiliki tingkat akurasi yang lebih tinggi. Tingkat akurasi ini juga memiliki aspek ekonomis yang terkait dengan cost inventory. Jika dihitung berdasarkan analisis metode linear, eksponensial dan polinomial diperoleh perbedaan biaya Rp.11,04 Milyar, Rp. 3.45 Milyar dan Rp. 345 Juta, dengan demikian diketahui pula bahwa biaya yang dikeluarkan untuk inventory cost menggunakan metode polinomial lebih hemat.
\end{abstract}

Kata Kunci: Undercarriage, Tren Analisis, Metode Polinomial

\section{Pendahuluan}

Penelitian ini dilakukan dalam rangka mencari solusi atas masalah yang dihadapi oleh perusahaan yang bergerak dibidang penyediaan, perawatan dan penggantian komponen kerangka bawah dari suatu alat berat atau yang sering juga disebut undercarriage. Selain menjual suku cadang alat berat khususnya komponen undercarriage, perusahaan juga memberikan pelayanan purna jual kepada para pelanggannya. Salah satu bentuk layanan purna jual yang disediakan adalah pemeriksaan kondisi undercarriage disebut Quality Track Services(QTS) [10] 
Quality Track Services adalah sebuah layanan yang terdiri dari:

1. Pemeriksaan dan pengukuran komponen undercarriage.

2. Perhitungan keausan komponen undercarriage.

3. Rekomendasi atas perkiraan waktu penggantian masing-masing komponen undercarriage.

Rekomendasi atas perkiraan jumlah pemakaian komponen undercarriage dalam kurun waktu tertentu atau yang disebut dengan forecast.

Dari ke-4 tahap QTS tersebut, hanya tahap pertama yang dilakukan di lapangan, yaitu pengukuran komponen undercarriage, sedangkan 3 tahap berikutnya adalah pengolahan data, yang selama ini dilakukan dengan bantuan software spreed sheet masalah yang muncul adalah seberapa tinggi tingkat keakuratan terhadap pengukuran dan pengolahan data yang sudah dilakukan. Untuk itu perusahaan memandang perlu untuk menetukan metode yang tepat sehingga hasil pengukuran komponen undercarriage dapat diolah agar bisa memperoleh tingkat keakuratan yang tinggi khususnya dalam penentuan kapan waktu penggantian komponen undercarriage

\section{Metoda Penelitian}

Perhitungan keausan undercarriage dihitung dengan[11].

$$
y_{2}=\frac{s t d-a c t}{s t d-\ln t} x 100 \%
$$

Sedangkan untuk penentuan waktu penggantian Undercarrriage digunakan metode

- Metode ekstrapolasi linear

- Metode ekstrapolasi eksponensial (quadratic)

- Metode ekstrapolasi dengan membaca table

- Metode ekstrapolasi polynomial
Metode Ekstrapolasi Linear

Metode ekstrapolasi linear ini dapat ditunjukkan pada gambar 1 berikut ini:

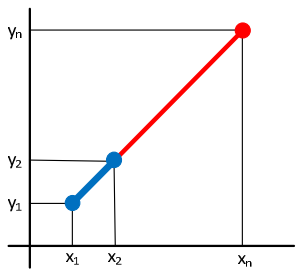

Gambar 1. Ekstrapolasi Linier

Dari diagram tersebut dapat diketahui rumus dasar persamaan linear adalah[3]:

$$
\frac{x_{\mathrm{n}}-x_{1}}{y_{n}-y_{1}}=\frac{x_{2}-x_{1}}{y_{2}-y_{1}}
$$

Jika yang akan diprediksi adalah jam waktu penggantian komponen, maka rumus akan diubah menjadi:

$$
x_{n}=\frac{\left(y_{n}-y_{1}\right)}{\left(y_{2}-y_{1}\right)}\left(x_{2}-x_{1}\right)+x_{1}
$$

Penggantian komponen biasanya dilakukan saat keausan mencapai $120 \%$. Jika yang dipasang pada jam $x_{1}$ adalah komponen baru berarti keausan $y_{1}=0 \%$. Dengan demikian rumus pada persamaan di atas akan berubah menjadi:

$$
x_{n}=\frac{120 \%}{y_{2}}\left(x_{2}-x_{1}\right)+x_{1}
$$

dan tanggal penggantian komponen dapat diprediksi sebagai berikut:

$$
D_{n}=D_{2}+\frac{\left(x_{n}-x_{2}\right)\left(D_{2}-D_{1}\right)}{x_{2}-x_{1}}
$$

\section{Metode Ekstrapolasi Eksponensial (Kuadratik)}

Metode ekstrapolasi eksponensial atau ekstrapolasi kuadratik atau ekstrapolasi hyperbolik ini dapat dilakukan apabila diketahui tiga pasang data. Ilustrasinya dapat dilihat dalam Gambar 2 : 


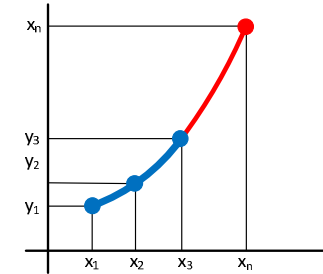

Gambar 2. Ekstrapolasi Eksponensial

Rumus umum yang digunakan:

$y_{n}=a_{1} x_{n}{ }^{k_{\mathrm{D}}}+a_{2} x_{n}{ }^{k_{1}}+a_{3} x_{n}{ }^{k}$

yang disederhanakan menjadi[11]

$$
y=a x^{k}
$$

\section{Metode Ekstrapolasi dengan Pembacaan Tabel}

Metode ini dikembangkan oleh produsen alat berat dari Amerika, metode ini tidak menghitung keausan material menghitung "Keausan Waktu". Keausan waktu mempertimbangkan keausan yang lambat saat lapisan keras masih ada dan keausan lebih cepat ketika sampai ke material yang lebih lunak. Untuk menemukan keausan waktu, kita memerlukan tabel Custom Track Service (CTS) yang dikeluarkan oleh pabrik.

Tabel 1 Custom Track Service Handbook (CTS) [14]

ra

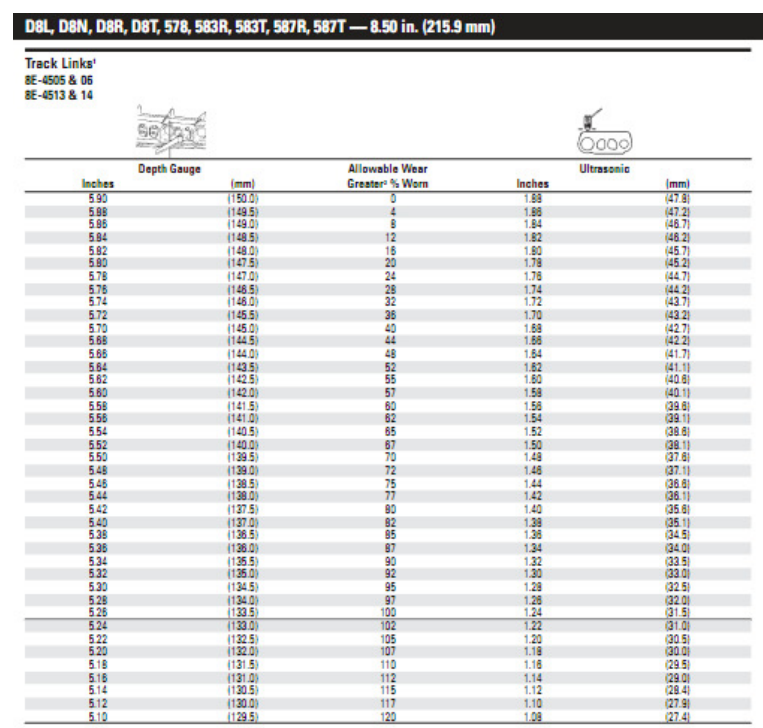

\section{Ekstrapolasi Polinomial}

Metode Ekstrapolasi Polinomial melakukan proyeksi umur dengan menggunakan data-data pengukuran yang telah lampau rumus yang digunakan adalah[11]:

$$
y_{n}=a_{1} x_{n}{ }^{0}+a_{2} x_{n}{ }^{1}+a_{3} x_{n}{ }^{2}+\cdots+a_{n} x_{n}^{n}
$$

Gambar 3 adalah adalah contoh penggunaan ekstrapolasi polinomial.

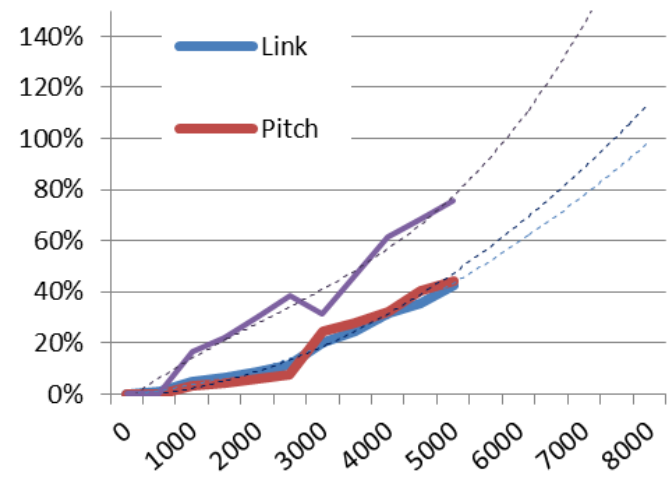

Gambar 3. Contoh ekstrapolasi polinomial

\section{Metode Analisis Pengolahan Data}

Pendekatan dengan metode Regresi Linier di mulai dengan mendefenisikan persamaan garis lurus (linear)[4]. Persamaan garis lurus (linear) dapat difenisikan sebagai berikut:

$$
y=m x+b
$$

dimana

$$
m=\frac{n \sum\left(x_{i} y_{i}\right)-\sum x_{i} \sum y_{i}}{n \sum\left(x_{i}^{2}\right)-\left(\sum x_{i}\right)^{2}}
$$

dan

$$
b=\frac{\sum y_{i}-m \sum x_{i}}{n}
$$

Dengan menghitung nilai $m$ dan $\mathrm{b}$ pada persamaan di atas tingkat akurasi data-data point ditentukan melalui koefisien korelasi $r$, dimana nilai korelasi ini ditentukan dengan rumus berikut:

$$
r=\frac{n \sum(x y)-\sum x \sum y}{\sqrt{\left[n \sum\left(x^{2}\right)-\left(\sum x\right)^{2}\right]\left[n \sum\left(y^{2}\right)-\left(\sum y\right)^{2}\right]}}
$$


Dalam metode eksponensial,untuk menyederhanakan solusi persamaan eksponensial $y=C x^{2}[4]$, maka digunakan analisis regresi linear yaitu merubah persamaan eksponensial menjadi persamaan linear dengan menambahkan logaritma pada ruas kiri dan kanan sehingga penurunan persamaan ditunjukkan sebagai berikut [4]:

$$
\begin{aligned}
& \ln y=\ln \left(C x^{p}\right) \\
& =\ln C+p \ln x
\end{aligned}
$$

Dimana parameter $p$ ditentukan dengan:

$$
p=\frac{n \sum\left(\ln x_{i} \ln y_{i}\right)-\sum \ln x_{i} \sum \ln y_{i}}{n \sum\left(\ln x_{i}^{2}\right)-\left(\sum \ln x_{i}\right)^{2}}
$$

Sedangkan konstanta $\mathrm{C}$ ditentukan dengan:

$$
C=\frac{\sum \ln y_{i}-p \sum \ln x_{i}}{n}
$$

Metode polynomial dilakukan konversi menjadi ekspresi matrik yang kemudian dapat diselesaikan dengan menggunakan beberapa metode matrik atau determinan.

$$
\{\mathrm{Y}\}=[\mathrm{X}]\{\mathrm{A}\}
$$

Untuk menghitung nilai vektor $\{\mathbf{A}\}$ dapat dilakukan dengan beberapa metode (Al-Khafaji \& Tooley, 1986), namun cara yang paling sederhana adalah metode Cramer. Langkah awal metode ini menghitung determinan matrik $[\mathrm{X}]$ dengan melibatkan vektor $\{\mathrm{Y}\}$ sebagai berikut:

$\operatorname{det}[X]=\left[\begin{array}{ccccccc}1 & x_{1} & x_{1}^{2} & x_{1}^{3} & \square & \square & x_{1}^{n} \\ 1 & x_{2} & x_{2}^{2} & x_{2}^{3} & \square & \square & x_{2}^{n} \\ 1 & x_{3} & x_{3}^{2} & x_{3}^{3} & \square & \square & x_{3}^{n} \\ \square & \square & \square & \square & \square & \square & \square \\ \square & \square & \square & \square & \square & \square & \square \\ 1 & x_{n+1} & x_{n+1}^{2} & x_{n+1}^{3} & \square & \square & x_{n+1}^{n}\end{array}\right]$

$$
\operatorname{det}[X]_{i}=\left[\begin{array}{ccccccc}
1 & x_{1} & x_{1}^{2} & \ldots . . x_{1}^{i-1} & y_{1} & x_{1}^{i+1} \ldots & x_{1}^{n} \\
1 & x_{2} & x_{2}^{2} & \ldots x_{2}^{i-1} & y_{2} & x_{2}^{i+1} \ldots & x_{2}^{n} \\
1 & x_{3} & x_{3}^{2} & \ldots x_{3}^{i-1} & y_{3} & x_{3}^{i+1} \ldots & x_{3}^{n} \\
\square & \square & \square & \square & \square & \square & \square \\
\square & \square & \square & \square & \square & \square & \square \\
1 & x_{n+1} & x_{n+1}^{2} & \ldots x_{n+1}^{i-1} & y_{n+1} & x_{n+1}^{i+1} \ldots & x_{n+1}^{n}
\end{array}\right]
$$

$$
i=0,1,2, \ldots . ., \mathrm{n} \quad a_{i}=\frac{\operatorname{det}[\mathrm{X}]_{i}}{\operatorname{det}[\mathrm{X}]}
$$

Nilai determinan dari matrik [X] mengekpresikan nilai detrminan dari matrik [X] yang kolom i diganti dengan vektor $\{Y\}$. Selanjutnya nilai masing-masing koefisien di hitung berdasarkan persamaan.

Adapaun komponen undercarriage yang di jadikan penelitian adalah bushing yang terdapat padaTrack Link. Berikut adalah gambarnya.

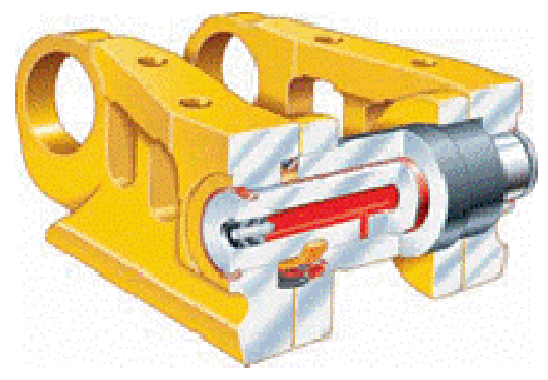

Gambar 4. Bushing yang terdapat pada Track Link

Pengukuran yang dilakukan gambarnya adalah

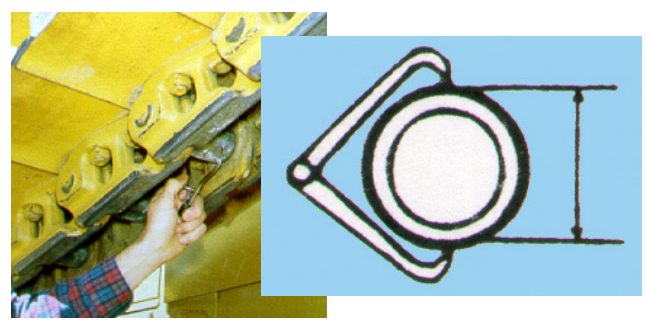

Gambar 5. Pengukuran Bushing 


\section{Hasil dan Pembahasan}

Penelitian yang dilakukan memberikan hasil berupa data real pengukuran/inspeksi dilapangan dari salah satu unit alat berat yang dimiliki oleh salah satu pelanggan perusahaan.Pengukuran/inspeksidilakukan sebanyak 8 kali untuk 19 item pengukuran komponen undercarriage dalam rentang waktu mulai dari 19 Desember 2010 sampai dengan 07 Februari 2012.

Untuk setiap pengukuran pada komponen Bushing diperoleh data prosentase keausan seperti pada tabel $4.2 \mathrm{di}$ bawah ini:

Tabel 2. Pengukuran Bushing

\begin{tabular}{|c|c|c|c|}
\hline \multirow{2}{*}{ Tanggal } & \multirow{2}{*}{ SMR } & \multicolumn{2}{|c|}{ Standar: 81 Limit: 72 (mm) } \\
\cline { 3 - 4 } & & Actual (mm) & Keausan (\%) \\
\hline $09 / 12 / 2010$ & 28713 & 81.0 & 0 \\
\hline $13 / 01 / 2011$ & 29247 & 80.5 & 6 \\
\hline $24 / 02 / 2011$ & 30060 & 80.5 & 6 \\
\hline $25 / 03 / 2011$ & 30559 & 80.0 & 11 \\
\hline $03 / 06 / 2011$ & 31916 & 79.0 & 22 \\
\hline $27 / 09 / 2011$ & 33607 & 74.0 & 78 \\
\hline $08 / 12 / 2011$ & 33736 & 73.0 & 83 \\
\hline $07 / 02 / 2012$ & 33804 & 71.0 & 111 \\
\hline
\end{tabular}

Pada tabel 2, kolom sebelah kanan merupakan prosentase keausan dan sebelah kiri merupakan kolom untuk SMR atau waktu penggantian. Mulai prosentase $0 \%$ s.d $111 \%$ merupakan data pengukuran sebenarnya sedangkan untuk prosentase $120 \%$ merupakan data prediksi untuk penggantiaan undercarriage. Dari data di atas dibuat grafik perbandingan sebagai berikut:

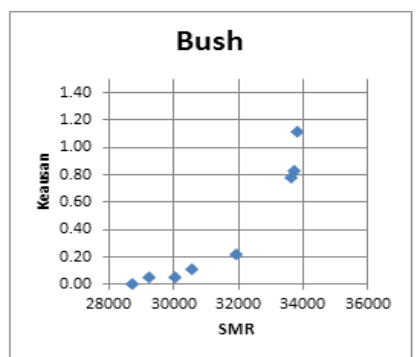

Gambar 6. SMR vs Keausan Bushing

Dari data pengukuran dan grafiknya akan dibandingkan menggunakan metode Linier,
Eksponensial dan Polinomial. Untuk metode linier menggunakan hasil yang terdapat pada tabel 2 didapatkan grafiknya seperti gambar 7 .

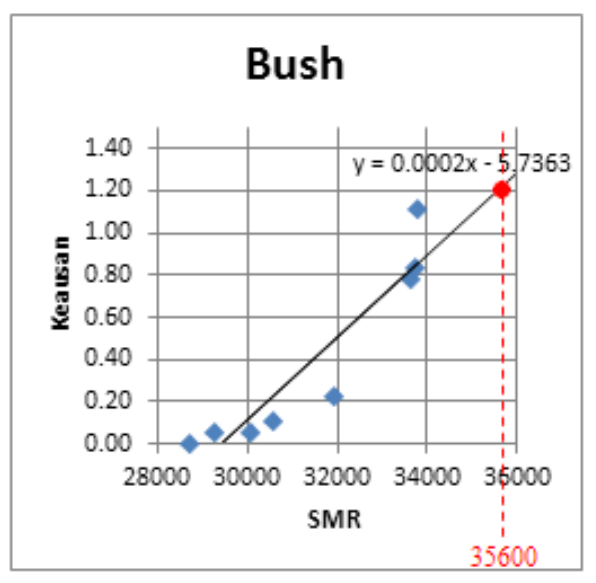

Gambar 7. Trenline Linier

Selanjutnya pada metode eksponensial $\left(\mathrm{y}=\mathrm{Cx}^{\mathrm{p}}\right)$, dengan melakukan proses yang sama seperti pada analisis regresi linier serta mengolahnya seperti tabel 2 grafik persamaannya seperti gambar 8 .

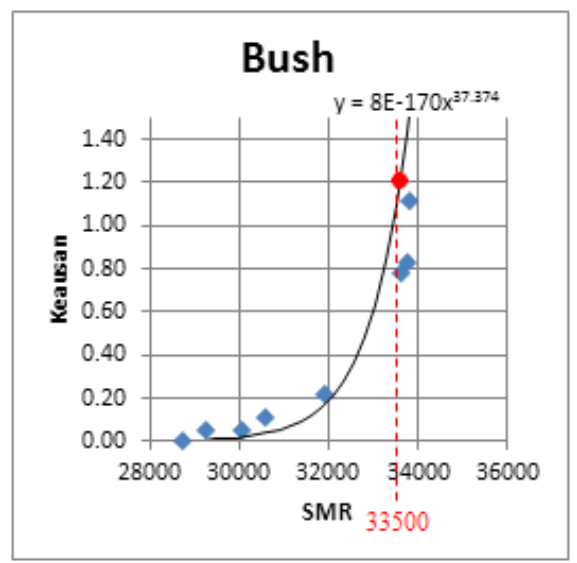

Gambar 8. Metode Eksponensial Bushing

Untuk metode polinomial, dari tabel 4.4 Pengukuran Bushing diekspresikan sebuah fungsi polinomial dari grafik dimana Keausan (y) dan SMR (x) menjadi $y=f(x)$ dengan asumsi bahwa data pada tabel 2 terletak pada grafik maka dibuat bentuk umum persamaan polinomial berikut:

$$
y=a_{3} x^{3}+a_{2} x^{2}+a_{1} x+a_{0}
$$


Grafik yang dihasilkan adalah sebagai berikut:

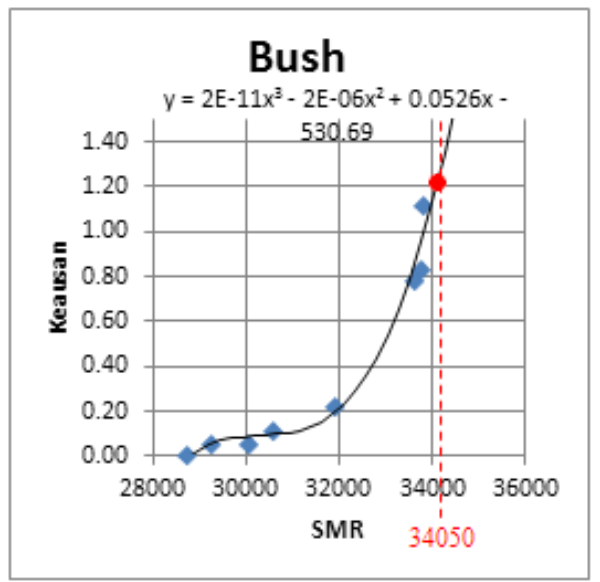

\section{Gambar 4.5. Trendline Polinomial}

Dengan demikian apabila di gabungkan untuk semua metode penentuan waktu penggantian diperoleh seperti tabel 3

Table 3. Perbandingan Metode Perkiraan SMR

\begin{tabular}{|l|c|c|c|}
\hline \multicolumn{1}{|c|}{ Metode } & Keausan & SMR & $\begin{array}{c}\text { Perbedaan } \\
\text { (Jam) }\end{array}$ \\
\hline Real & $120 \%$ & 34000 & 0 \\
\hline Linier & $120 \%$ & 35600 & 1600 \\
\hline Eksponensial & $120 \%$ & 33500 & 500 \\
\hline Polinomial & $120 \%$ & 34050 & 50 \\
\hline
\end{tabular}

Dari tabel di atas terlihat jelas bahwa pengukuran dengan metode polinomial memiliki tingkat akurasi yang lebih tinggi untuk memperkirakan waktu penggantian komponen undercarriage yakni perbedaan-nya 50 jam.

\section{Kesimpulan}

Analisa Metode Penentuan Waktu Penggantian Quality Track Service(QTS) komponen Undercarriage diperlukan untuk dapat membandingkan tingkat keakuratan data yang dihasilkan dan diprediksikan dari pengukuran keausan.Dari hasil analisa data penelitian dapat ditarik kesimpulan sebagai berikut:

1. Perhitungan waktu penggantian komponen undercarriage berdasarkan data histori hasil pengukuran untuk keausan $120 \%$ diprediksikan pada Service Meter Reading (SMR) 34000 jam;

2. Dari perbandingan metode analisis menggunakan regresi linear, eksponensial dan polinomial di dapatkan hasil trend analisis perbedaan 1600 jam, 500 jam dan 50 jam. Berarti metode polinomial lebih akurat;

3. Aspek ekonomis dari biaya yang dikeluarkan untuk inventory cost metode regresi linier sebanyak Rp. 11.04 Milyar, metode eksponensial Rp. 3.45 Milyar dan polinomial Rp. 345 Juta. Sehingga metode polinomial lebih ekonomis dibandingkan yang lainnya.

\section{Saran}

Untuk dapat meningkatkan aspek managerial perusahaan khususnya keakuratan data waktu penggantian komponen undercarriage sehingga dapat menghemat biaya yang sia-sia, penulis memberikan saran yang diharapkan dapat berguna untuk meningkatkan sistem QUALITY TRACK SERVICE (QTS) komponen underccariage :

1. Perlu melakukan pengukuran /inspeksi yang rutin dan disiplin setiap bulan agar diperoleh data yang lebih akurat karena pada prinsipnya makin banyak datanya maka pengukuran/prediksi semakin akurat.

2. Supaya diperoleh data yang lebih lengkap sebaiknya di perhatikan/ diperhitungkan pula faktor-faktor yang menentukan keausan komponen undercarriage seperti faktor tanah dan lingkungan dimana unit atau komponen tersebut beroperasi.

3. Seiring dengan perkembangan teknologi informasi dewasa ini sudah seharusnya perusahaan memanfaatkan media website/ internet untuk mengembangkan sistem informasi perusahaan termasuk sistem databasenya. 


\section{Daftar Pustaka}

[1] Al-Khafaji, A. W., \& Tooley, J.R (1986) Numerical Methods in Engineering Practice. New York: CBS College Publishing.

[2] Dikmenjur,.(2004)Melaksanakan Pekerjaan Dasar Undercarriege ABMR 011.21-1.A.

[3] Gustafsson Bertil,. (2011) Fundamentals of Scientific Computing $\bigcirc \quad$ Springer-Verlag Berlin Heidelberg.

[4] Karmiadji, D.W. (2009) OPTIMASI DESAIN Material, komponen, konstruksi teori dasar dan aplikasi

[5] Luntungan, Sonny,.Undercarrieage APLTCLO40 (C) Caterpillar of Australia Pty Ltd.

[6] Nur, Deni Ardian,. (2008) Analisa Kerusakan Komponen Undercarriage pada unit Dozer Komatsu D155-2”.

[7] Pahl, G. and Beitz, W. (2007) EngineeringDesign:A Systematic Approachthird Edition Springer
[8] Perillo, Marco and Team (2008) Structural dynamic response of track chain complete undercarrieage system using a virtual proving ground approach.

[9] Rusinski, E. and Team (2009) Half shaft undercarriage systems designing and operating problems Journal of achievement in Materials and Manufacturing Engineering V.33 Issue 1.

[10] Sarno,. (2008) Undercarriage TrainingPT Haneagle Heavyparts Indonesia

[11] Sarno,.(2012) Variable for Undercarriage Life (Presentation) PT

[12] Yamit, Zulian., Drs. M. Si (1996) Manajemen Produksi dan Operasi, EKONOSIA Kampus Fakultas Ekonomi UII Yogyakarta. - Ed.1.

[13] --------..Custom Track Service (CTS)Handbook Caterpilar ${ }^{\circledR} 16$ th Edition 